\title{
Peran Guru Dalam Proses Pembelajaran PAK Terhadap Minat Belajar Siswa Kristen SMA Kelas X-XII Di Bukit Shalom Ubud
}

\author{
Juari Lugan, Sarce Rien Hana
}

\begin{abstract}
Abstrak
Peran guru dalam dunia pendidikan sangat penting khususnya dalam belajar dan mengajar dengan tujuan menolong siswa untuk mengenal dunia pendidikan dari yang tidak tahu menjadi tahu, terlebih untuk mengenal kebenaran Allah. Keadaan lingkungan dapat mempengaruhi seorang dalam belajar karena itu peran guru dalam proses belajar sangat diperlukan agar minat belajar siswa dapat meningkat khususnya dalam mata pelajaran PAK. Tujuan penulisan skripsi ini adalah bagaimana peran guru dapat meningkatkan minat belajar siswa khususnya mata pelajaran PAK.

Alasan penulis mengangkat judul penulisan skripsi ini dikarnakan selama penulis melaksanakan praktik di GKII Bukit Shalom Ubud, penulis memperhatikan bahwa siswa kristen termasuk minoritas di setiap sekolah yang ada di Gianyar, dan tidak ada guru yang mengajar mata pelajaran PAK. Oleh karena itu gereja dipercayakan untuk menangani mata pelajaran Pendidikan Agama Kristen, dan satu hal yang penulis perhatikan selama ada di sana siswa sangat berantusias mengikuti kelas PAK. Dikarenakan itu penulis ingin mengetahui apa yang menjadi peran guru dalam proses pembelajaran PAK untuk meningkatkan minat belajar siswa. Adapun metode yang digunakan penulis dalam penulisan karya ilmiah ini adalah metode kualitatif dengan mengunakan pengumpulan data sebagai berikut: studi kepustakaan dan melakukan wawancara terhadap guru PAK serta siswa Kristen yang mengikuti pelajaran PAK di GKII Bukit Shalom Ubud. Dari hasil penelitian yang sudah dilakukan maka penulis menarik kesimpulan bahwa peran seorang guru PAK sangat mempengaruhi minat belajar siswa baik itu persiapan guru secara koqnitif, keterampilan mengelola dalam kelas, metode yang digunakan, maupun hubungan guru secara emosianal dengan siswa sangat menentukan minat belajar siswa.
\end{abstract}

Kata- kata Kunci: Peran Guru, Metode Mengajar, Minat Belajar.

\section{Pendahuluan}

\section{Latar Belakang Masalah}

Dalam dunia pendidikan peran guru sangatlah penting karena berkaitan dengan belajar dan mengajar dimana seorang guru akan menolong siswa mengenal dunia pendidikan dari yang tidak tahu menjadi tahu.Menurut John Nainggolan menyatakan bahwa:

Guru merupakan unsur yang penting dalam kegiatan belajar dan mengajar, karena guru yang membantu perserta didiknya untuk belajar mengenal, memahami, dan menghadapi dunia dimana ia berada. Dunia yang dimaksud adalah dunia pengetahuan, 
dunia iman, dunia karya, dan dunia sosial budaya. Di sini guru sebagai jembatan sekaligus agen agar perserta didik dapat berdialog dengan dunianya. Oleh sebab itu proses belajar mengajar dapat berjalan dengan baik apa bila ada guru dan murid, di mana guru berfungsi sebagai pemberi materi karena itu guru merupakan faktor penting dalam menyukseskan kegiatan belajar mengajar. Di mana ada kegiatan belajarmengajar berlangsung, di situ mengharapkan guru yang berkualitas. ${ }^{1}$

Dapat dikatakan bahwa guru memiliki peran yang begitu penting dalam dunia pendidikan mulai dari tingkat bawah sampai dengan tingkat atas. Dan ini juga berlaku bagi seorang guru yang mengajar di bidang agama Kristen di mana ia akan menolong para perserta didiknya untuk mengenal sang pencipta (Allah) tidak hanya sebatas itu ia juga (guru) akan membantu agar perserta didik memiliki iman yang kuat dalam Kristus Yesus sepanjang hidupnya. Oleh sebab itu menjadi guru agama Kristen bukanlah satu hal yang muda karena ini merupakan pekerjaan yang mulia, panggilan yang istimewa dikhususkan, berbeda dengan guru-guru yang lainnya. Seorang pendidik yang mengajar di bidang kekristenan akan membawa perserta didik untuk mengenal Kristus Yesus secara benar sesuai dengan ajaran alkitab.

Tujuan akhir PAK: Kita mengajar agar melalui pengajaran kita, Allah dapat berkerja di hati mereka yang kita ajar untuk menjadikan mereka murid-murid yang meyakinkan baik dengan kata-kata maupun dengan perbuatan di tengah-tengah dunia." ${ }^{2}$ Akhir dari suatu pengajaran tentu ada hal yang hendak dicapai, begitu pula dalam pengajaraan PAK dengan harapan bahwa perserta didik dapat belajar banyak hal tentang kekristenan, mengenal Kristus dengan benar agar setiap individu-individu siswa memiliki iman yang teguh dan itu dapat diaplikasikan dalam perkataan maupun perbuatan yang menjadi pedoman di dalam kehidupan secara nyata. Dengan demikian siswa dapat bertumbuh dewasa secara spiritual tentunya dengan pertolongan Roh Kudus, karena itu pelajaran PAK sangatlah penting bagi siswa kristen.

B Samuel Sijabat dalam buku, Strategi Pendidikan Kristen mengatakan:

Perlu disadari oleh seorang guru konteks sosial dan budaya dimana seorang berada sangat mempengaruhi pristiwa dan hasil belajarnya seorang. Apa yang dipelajari dan bagaimana proses belajar yang dialami tidak lepas dari nilai budaya yang membentuknya sejak kecil. Konsep ruang dan waktu, pola komunikasi, pola berfikir, otoritas gaya kepemimpinan, cara menghadapi konflik yang dipelajari seseorang, guru maupun perserta didik. Dari lingkungan budayanya akan mempengaruhi bentuk pemahamannya tentang tugas belajar dan mengajar. ${ }^{3}$

Ketika seorang hidup di tengah-tengah mayoritasnya belum percaya keadaan lingkungan atau budaya akan mempengaruhi diri seseorang, mulai dari karakter, pola pikir dan juga cara belajar akan mempengaruhi minat belajarnya. Jika lingkungan akan mempengaruhi hasil belajar seorang peserta didik dan mendapat hal yang positif tentu

${ }^{1}$ John M. Nainggolan, Guru Agama Kristen Sebagai Panggilan dan Profesi (Bandung: Bina Media Informasi, 2010), 22.

${ }^{2}$ Daniel Nuhamara, Pembimbing PAK (Bandung: Jurnal Info Media 2007),30.

${ }^{3}$ B Samuel Sidjabat, Strategi Pendidikan Kristen (Yogjakarta: Andi Offset, 1999), 85. 
sesuatu yang sangat baik, karena lingkungan memberi pengaruh yang baik sehingga peserta didik memiliki minat balajar yang baik pula tetapi sebaliknya jika lingkungan memberi pengaruh yang buruk di mana perserta didik kurang berminat dalam belajar akan memberi masalah bagi masa depan perserta didik apa lagi kalau itu berhubungan dengan pendidikan agama kristen karena menyangkut kehidupan spiritual perserta didik. Seperti yang sudah diketahui bersama bahwa PAK sangat berpengaruh dalam kehidupan rohani seorang tetapi ada kalanya karena faktor lingkungan secara tidak langsung akan terpengaruh.

Jhon M. Nainggolan menyatakan:

Gereja tempat pertama bagi penyelengaraan PAK bagi mereka. Dalam membangun iman jemaat dari gerejalah PAK akan terus berkembang keluar dalam masyarakat, sekolah dan keluarga. PAK merupakan tugas terutama oleh karena itu harus dilakukan dengan sungguh-sungguh karena keberhasilan PAK akan ditentukan oleh gereja, PAK mendapatkan tempat yang sangat penting dari seluruh pelayanan yang ada di gereja karena gereja akan mengalami pertumbuhan yang baik bila ada pengajaran di dalam gereja tersebut lewat pengajaran jemaat akan mengalami pertumbuhan iman dan perubahan hidup. ${ }^{4}$

Bali termasuk mayoritas orang-orang yang belum percaya, kebanyakan masyarakat yang ada di Bali adalah Hindu dan orang Kristen sebagai minoritas di tempat ini. Begitu juga dalam pendidikan Sekolah Menengah Atas ada beberapa sekolah tidak memiliki guru yang mengajar di bidang kekristenan khususnya di kabupaten Gianyar oleh sebab itu sekolah memberi kepercayaan untuk gereja dalam menangani Pendidikan Agama Kristen bagi setiap siswa khususnya Sekolah Menengah Atas.Gereja GKII Bukit Shalom Ubud di mana tempat penulis berpraktik adalah salah satu gereja yang mengambil alih dalam mengajar PAK bagi siswa SMA yang ada di Gianyar dan diikuti oleh dominasi gereja lain, kelas PAK di adakan setiap hari minggu mulai dari tingkat SD-SMA dan merupakan kesempatan bagi seorang guru untuk menanamkan nilai-niilai kekristenan bagi penerus gereja khususnya anak-anak muda (SMA) pergunakan waktu dengan baik yang sudah di percayakan. Gerejalah tempat di mana setiap individu siswa mendapat pendidikan PAK secara formal. Menurut penulis ini suatu yang sangat penting dan kesempatan bagi seorang guru untuk memperkenalkan Kristus dengan harapan terbentuknya moral yang segambar dan serupa dengan Allah dan berdampak di tengah masyarakat, keluarga terlebih bagi mereka yang belum percaya. Seperti yang sudah penulis sampaikan di atas bahwa lingkungan kadang kala mempengaruhi perserta didik untuk kurang dalam meminati kelas PAK disini seorang guru mempunyai tanggung jawab untuk menolong perserta didik agar bisa giat dalam mengikuti kelas PAK .

\section{Pokok Masalah}

Berdasarkan latar belakang di atas, maka yang menjadi pokok masalah dalam penulisan skripsi ini adalah:bagaimana peran guru dalam proses pembelajaran PAK untuk meningkatkan minat belajar siswa SMA bukit shalom Ubud?

\section{Tujuan Penelitian}

\footnotetext{
${ }^{4}$ John M. Nainggolan, PAK Dalam Masyrakat Majemuk (Bandung: Bina Media Informasi, 2009), 14-
} 15. 
Berdasarkan pokok masalah di atas, maka penulis menguraikan tujuan penulisan sebagai berikut: untuk menjelaskan peran guru dalam meningkatkan minat belajar siswa khususnya mata pelajaran PAK.

\section{Manfaat Penelitian}

Beberapa mamfaat yang hendak dicapai sehubungan dengan penulisan skripsi ini sebagai berikut:

Pertama, agar penulisan ini dapat memberkati serta menambah wawasan bagi penulis dan pembaca.

Kedua, agar karya tulis ini dapat dijadikan sebagai pedoman bagi guru PAK khususnya gereja yang menangani PAK.

Ketiga, sebagai salah satu persyaratan akademik Sekolah Tinggi Theologia Jaffray Makassar untuk mencapai gelar sarjana.

\section{Metode Penelitian}

Dalam penulisan skripsi ini penulis menggunakan penelitian kualitatif dengan teknik pengumpulan data sebagai berikut:

Pertama, penulis akan menggunakan metode penelitian kepustakaan yaitu penelitian terhadap buku-buku yang berkaitan dengan pembahasan skripsi.

Kedua, mengobservasi setiap objek yang menjadi bahan penelitian dan wawancara.

\section{Batasan Penelitian}

Penulisan skripsi ini diperlukan batasan untuk mempermuda penulis dalam meneliti dan menulis topik pembahasan. Penulisan ini hanya berkisar pada peranan guru PAK dalam meningkatkan minat belajar siswa Kristen SMA kelas X, XI, dan XII Bukit Shaalom Ubud.

\section{Kesimpulan}

Peran guru dalam proses pembelajaran PAK untuk meningkatkan minat belajar siswa mendapatkan respons yang positif meskipun tidak secara keseluruhan adalah sebagai berikut:

Pertama, guru memiliki peran sebagai motivator untuk siswa, memberi dorongan dari luar dengan motivasi yang membangun. Selain itu guru juga menjadi Konselor bagi siswa didiknya siap mendengarkan apa yang menjadi pergumulan siswa baik secara pribadi maupun keluarga supaya hubungn secara emosional antara guru dan siswa dapat terjalin satu dengan lain.

Kedua, guru menjadi fasilitator untuk siswa memfasilitasi dalam belajar baik itu ruangan maupun materi yang akan siap diajarkan kepada siswa. Dan guru juga menjadi mediator sebagai jembatan bagi siswa untuk mengerti materi yang akan diajarkan.

Ketiga, metode dalam mengajar sangat mempengaruhi siswa untuk mengerti apa yang akan disampaikan oleh guru, seperti metode studi kasus dan tanya jawab, ceramah dan memiliki kemampuan dalam mengelola kelas. Mengunakan metode secara bervariasi perlu diperhatikan seorang pengajar, tidak fokus dengan satu metode saja dengan demikian siswa tidak bosan dalam belajar cara ini akan meningkatkan minat belajar siswa.

Keempat, siswa termotivasi mengikuti mata pelajaran PAK karena ada dorongan dari orang tua selain itu siswa juga harus memiliki motivasi dalam diri sendiri karena tidak cukup hanya dorongan dari luar tetapi harus ada dalam diri sendiri. 
Kelima, seorang guru harus mampu untuk mengelola kelas, agar terciptanya suasana belajar mengajar yang menyenangkan, membuat siswa merasa nyaman ada dalam kelas kalau kelas menyenangkan dan siswa merasa aman dengan sendirinya akan ada semangat untuk belajar.

Keenam, kurikulum sangat mempengaruhi untuk meningkatnya minat belajar, karena kurikulum sebagai panduan dalam mengajar membuat proses belajar mengajar terarah, terstruktur dengan baik.

Jadi, guru PAK sangat berperan terhadap minat belajar siswa, baik itu dalam persiapan guru secara kognitif maupun hubungan emosional guru dengan siswa serta kererampilan guru cara mengelola kelas.

\section{Kepustakaan}

Armstrong, Thomas. Kinds of Smart Menemukan Dan Meningkatkan Kecerdasan Anda Berdasarkan Teori. Jakarta: Gramedia Pustaka Utama, 2002.

Basrudin. Dkk. "Penerapan Metode tanya Jawab Untuk Meningkatkan Hasil Belajar Siswa Pada Pokok Bahasan Sumber Daya Alam Di Kelas IV SDN Farufia Kecamatan Bahodopi." Jurnal Kreatif Tadulako Online 1, No. 1 (2013):214-227. Diakses 21 Juni 2018.

https://media.neliti.com/media/publications/110168-ID-penerapan-metode-tanyajawab-untuk-menin.pdf

Brummelen, Harro Van. Batu Loncatan Kurikulum. Tangerang: Universitas Pelita Harapan, 2008.

Darmawan, I Putu Ayub. Menjadi Guru yang Terampil. Bandung: Kalam Hidup, 2014.

Day, Terry Jean. Kisah Tokoh-tokoh Alkitab Unik dalam Alkitab. Bandung: Kalam Hidup, 2012.

Darmadi, H. Pengembangan Model Metode Pembelajaran Dalam Diamika Belajar Siswa. Yogyakarta: Budi Utama, 2017.

Fatmawati, Erma. Profil Pesantren Mahasiswa: Karakteristik Kurikulum, Desain Pengembangan Kurikulum, Peran Pemimpin Pesantren. Yogyakarta: LKIS Pelangi Aksara 2015.

Harsanto, Radno. Pengelolaan Kelas Yang Dinamis. Yogyakarta: Kanisius, 2011. Herijulianti, E., Dkk. Pendidikan Kesehatan Gigi. Jakarta: Buku Kedokteran, 2002. Hakim, Thursan. Belajar Secara Efektif. Jakarta: Puspa Swara, Anggota IKAPI, 2008. Johnson, Elaine B. Contextual Teaching \& Learning Menjadikan Kegiatan BelajarMengajar Mengasikkan dan Bermakna. Bandung: Penerbit MLC, 2007.

Kuhns, Janet. "Mengajar Secara Kreatif" Jurnal Jaffray [Online], Volume 1 Nomor 1 (5 Januari 2005)

Kurniasih, I., Berlin Sani. Mengajar Sukses Panduan Lengkap Menjadi Guru Kreatif dan Inovatif. Yogyakarta: Pustaka Diantara 2017.

Kristiawan, M., Dkk. Manajemen Pendidikan. Yogyakarta: Budi Utama 2017.

Mahdalena, Sri. "Pengunaan Metode Tanya Jawab Untuk Meningkatkan Hasil Belajar Siswa Pada Pelajaran PKN di Kelas V." Jurnal Penelitian dan Pembelajaran 3, No. 3 
(2014):1-14. Diakses 21 Juni 2018.

http://jurnal.untan.ac.id/index.php/jpdpb/article/download/4919/pdf.

Nasution, T., Nurhalijajah Nasution. Peranan Orang Tua Dalam Meningkatkan Prestasi Belajar Anak. Jakarta: Gunung Mulia, 1989.

Nainggolan, John M. Guru Agama Kristen Sebagai Panggilan dan Profesi Bandung: Bina Media Informasi, 2010.

PAK Dalam Masyrakat Majemuk. Bandung: Bina Media Informasi, 2009.

Nuhamara, Daniel. Pembimbing PAK. Bandung: Jurnal Info Media, 2007

Surbakti, E. B. Questions Answers Teenagers. Jakarta: Elex Kamputindo, 2011.

Retnowati. Perempuan-perempuan Dalam Alkitab. Jakarta: BPK Gunung Mulia, 2011.

Sidjabat, B Samuel. Strategi Pendidikan Kristen. Yogyakarta: Andi Offset 1999.

Sanjaya, Wina. Strategi Pembelajaran Berorentasi Standar Proses Pendidikan. Jakarta: Kencana, 2014.

Salman, Muh Syukur. Menjadi guru yang dicintai siswa. Yogyakarta: Deepublish 2015.

Sidjabat, B. S. Mengajar Secara Profesional. Bandung: Kalam Hidup, 2014.

Stefanus, Daniel. Sejarah PAK Tokoh-tokoh Besar PAK. Bandung: Bina Media Informasi. 2009.

Susanto, Ahmad. Teori Belajar dan Pembelajaran di Sekolah Dasar. Jakarta: Prenada media Group, 2016.

Saifuddin. Pengelolan Pembelajaran Teoretis dan Praktis. Yogyakarta: Budi Utama 2015.

Sumar, Warni T., Intan Abdul Razak. Strategi Pembelajaran Salam Implikasi Kurikulum Berbasis Soft Skill. Yogyakarta: Budi Utama, 2016.

Sunhaji. "Konsep Manajemen Kelas Dan Implikasinya Dalam Pembelajaran.” Jurnal Kependidikan 2, No 2 (2014):30-46. Diakses 25 Juni 2018.

https://media.neliti.com/media/publications/104713-ID-konsep-manajemen-kel as-dan-implikasinya.pdf

Surya, Hendra. Strategi Jitu Mencapai Kesuksesan Belajar. Jakarta: Elex Media Komputindo, 2011.

Syardiansah. "Hubungan Motivasi Belajar dan Minat Belajar Terhadap Prestasi Belajar Mahasiswa Mata Kuliah Pengantar Manajemen (Studi Kasus Mahasiswa Tingkat 1 EKM A Semester II).” Jurnal Manajemen dan Keuangan 5, No. 1 (2016):440-448. Diakses 15 Agustus 2018. http://ejournal.iainpurwokerto.ac.id/index.php/jurnalkependidikan/article/view/551/4 94

Tacoy, Selvester M. Membimbing dengan Hati Teori dan Teknik Konseling Alkitabiah. Jakarta: Media Gracia, 2011.

Toyyibah, Ibay. Cara Belajar Gue Banget. Jakarta: Elex Media Komputindo, 2017.

Uno, Hamza B., Nina Lematenggo. Tugas Guru Dalam Pembelajaran. Jakarta: Bumi Aksara, 2016.

Usman, Moh. Uzer. Menjadi Guru Profesional. Bandung: Remaja Rosdakarya, 1998.

Usman, Husaini., Purnomo setiadi Akbar, Metode Peneltian Sosial. Jakarta: Bumi Aksara 1996.

Widiasworo, Erwin. Cerdas Pengelolaan Kelas. Yogyakarta: Diva Press, 2018.

Wahidmurni. Evaluasi Pembelajaran Kopetensi dan Praktik. Yogyakarta: Nuha Litera, 2010. 
Wijaya, Hengki (ed.). Metodologi Penelitian Pendidikan Teologi. Makassar: Sekolah Tinggi Theologia Jaffray, 2016.

Yamin, Martinis Desain Pembelajaran Berbasis Tingkat Satuan Pendidikan. Jakarta: Referensi, 2013.

Yusuf, Ahmad M., Dkk. "Hubungan Metode Tanya Jawab dengan Minat Belajar Perserta Didik pada mata Pelajaran Agama Islam.” Jurnal Al-Thariqah 2, No. 1 (2017):89110. Diakses 21 Juni 2018. https://journal.uir.ac.id/index.php/althariqah/article/view/650 